\title{
Okul Öncesi Dönemde Alternatif Bir Eğitim Modeli: Waldorf Yaklaşımı ve Materyallerine Yönelik Öğretmen Görüssleri
}

Didem Kayahan Yüksel ${ }^{1}$

\author{
Sebahattin Kartal ${ }^{2}$
}

Type/Tür:

Research/Araştırma

Received/Geliş Tarihi:

December 6/6 Aralık 2019

Accepted/Kabul Tarihi:

January 6/ 6 Ocak 2020

Page numbers/Sayfa No: 845 -

859

Corresponding

Author/İletişimden Sorumlu

Yazar:

didemkayahan@cumhuriyet.ed $\underline{\text { u.tr }}$

\section{$\checkmark$ iThenticate}

This paper was checked for plagiarism using iThenticate during the preview process and before publication. / $\mathrm{Bu}$ çalışma ön inceleme sürecinde ve yayımlanmadan önce iThenticate yazılımı ile taranmıştır.

Copyright @ 2017 by

Cumhuriyet University, Faculty of Education. All rights reserved.

\section{Öz}

$\mathrm{Bu}$ araştırmanın amacı okul öncesi dönemde alternatif bir eğitim modeli olan Waldorf yaklaşımı ve materyallerine yönelik olarak okul öncesi öğretmenlerinin görüşlerini incelemektir. Araştırma nitel araştırma yöntemlerinden olgubilim desenine göre tasarlanmıştır. Araştırmada veri toplama amacıyla görüşme tekniği kullanılmış olup araştırmacı tarafından öğretmen görüşme formu geliştirilmiştir. Olasılıksız örnekleme yöntemlerinden amaçlı örneklemenin kullanıldığı araştırmanın katılımcıları sekiz okul öncesi öğretmeninden oluşmaktadır. Araştırmadan elde edilen verilerin analizinde MAXQDA 20 nitel veri analiz programı kullanılarak betimsel analiz yapılmıştır. Araştırma kapsamında Sivas Cumhuriyet Üniversitesi Eğitim Fakültesinde araştırmacı tarafından hazırlanan Waldorf materyalleri sergisi düzenlenmiştir. Sergide ayrıca bilgi verici Waldorf posterleri kullanılmış ve araştırmacılar tarafından katılımcı öğretmenlerin soruları yanıtlanmıştır. Araştırmadan elde edilen bulgulara göre; okul öncesi öğretmenleri Waldorf, Montessori ve Reggio Emilia alternatif eğitim yaklaşımları hakkında bilgi sahibidir. Öğretmenler, Waldorf eğitimi yaklaşımını çocuğun bireysel özelliklerini dikkate alması, yaratııılığına ve sanatsal gelişimine katkı sağlaması yönünden yararlı bulmakla birlikte Türk Eğitim Sistemi açısından uygulanabilirliği yönünden endişe duymaktadır. Waldorf materyallerinin öğretmen görüşlerine göre avantajları; öğrencinin yaratıcı düşünme becerilerine katkı sağlaması, ilgi çekici olması, kullanım kolaylığı, materyalin birden çok amaca hizmet etmesi, etkili öğretim ve motivasyon sağlaması şeklindedir. Öğretmenler tarafından materyallerin tanınırlı̆ın az olması ve maliyetli olması ise dezavantaj olarak değerlendirilmiştir. Öğretmenler, Waldorf materyallerini özellikle bilişsel becerilerin öğretiminde kullanabileceklerini belirtmiştir. Sınıflarında Waldorf materyallerini kullanmak istediklerini belirten öğretmenler bu konuda bilgi gereksinimleri olduğunu ve eğitim almak istediklerini ifade etmektedir.

Anahtar Kelimeler: Okul öncesi eğitimi, alternatif eğitim yaklaşımı, Waldorf eğitimi yaklaşımı, Waldorf materyalleri, materyal tasarımı.

\section{Suggested APA Citation/Önerilen APA Atıf Biçimi:}

Kayahan- Yüksel, D., \& Kartal, S. (2020). Okul öncesi dönemde alternatif bir eğitim modeli: Waldorf yaklaşımı ve materyallerine yönelik öğretmen görüşleri. Cumhuriyet International Journal of Education, 9(3), 845-859. http://dx.doi.org/10.30703/cije.656302

\footnotetext{
1 Dr. Öğr. Üyesi, Sivas Cumhuriyet Üniversitesi, Özel Eğitim Bölümü, Sivas/Türkiye Assist. Prof. Dr. Sivas Cumhuriyet University, Department of Special Education, Sivas/Turkey e-mail: didemkayahan@cumhuriyet.edu.tr ORCID ID: orcid.org/ 0000-0002-0184-6070

2 Dr. Öğr. Üyesi, Sivas Cumhuriyet Üniversitesi, Çocuk Gelişimi Bölümü, Sivas/Türkiye Assist. Prof. Dr. Sivas Cumhuriyet University, Department of Child Development, Sivas/Turkey e-mail: skartal@cumhuriyet.edu.tr ORCID ID: orcid.org/0000-0003-0976-0965
} 


\title{
An Alternative Preschool Education Model: Teachers' Perspectives on Waldorf Approach and Materials
}

\begin{abstract}
The aim of this study is to examine the views of pre-school teachers about Waldorf approach, which is an alternative education model in pre-school, and its materials. The research was designed according to the phenomenological pattern of qualitative research methods. Interview technique was used for data collection and teacher interview form was developed by the researcher. Participants of the study consisted of eight preschool teachers using purposeful sampling which is one of the improbable sampling methods. In the analysis of the data obtained from the research, descriptive analysis was carried out using MAXQDA 20 qualitative data analysis program. Within the scope of the research, Waldorf materials exhibition prepared by the researcher in Sivas Cumhuriyet University Faculty of Education was organized. Informational Waldorf posters were also used in the exhibition and the questions of the participating teachers were answered by the researchers. According to the findings; preschool teachers have knowledge about Waldorf, Montessori and Reggio Emilia alternative education approaches. Teachers find the Waldorf approach useful in terms of considering the individual characteristics of the child, contributing to their creativity and artistic development, but they are concerned about the applicability of this approach to Turkish education system. Advantages of Waldorf materials over teacher views; contributing to the creative thinking skills of the student, being interesting, ease of use, serving multiple purposes of the material, providing effective teaching and motivation. Being less recognized and costly materials were evaluated as disadvantages by teachers. Teachers stated that they can use Waldorf materials especially in teaching cognitive skills. Teachers who want to use Waldorf materials in their classrooms state that they need information and they want to get training on this issue.
\end{abstract}

Keywords: Preschool education, alternative education approach, Waldorf education approach, Waldorf materials, material design.

\section{Giriş}

Tarihsel süreç boyunca yaşanan değişimlerin, dirik bir yapı olan eğitim sistemini doğrudan etkilediği bilinmektedir. Klasik dönemin eğitime yüklediği "bilinçlice tanrıya ulaşma süreci" anlamından sonra (Kayg1sız, 1997; s.6) modern dönem beraberinde standartizasyon, sekronizasyonu ve merkezileşmeyi getirerek eğitim sistemlerini etkilemiş ve okulları zamanın gereklerini yerine getirebilen, benzer özelliklerdeki bireyleri yetiştirmeyi hedefleyen bir kalıba yerleştirmiştir (Gündüz, 2013). Modern dünyanın kurduğu bu eğitim sistemine yönelik en temel eleştirilerden biri tek tip düşünmeye ve davranmaya dayanması ve bireyselliği geri plana atmasıdır (Miller, 2010). Sisteme yönelik buna benzer eleştirilerin artması ile birlikte farklı alternatif eğitim yaklaşımları ortaya çıkmıştır. Rousseau, Pestalozzi, Montessori, Frobel ve Steiner gibi eğitimciler kendi eğitim felsefelerini yansıttıkları alternatif eğitim yaklaşımlarını tasarlamış ve uygulamıştır (Gündüz, 2013).

20. Yüzyıl ile başlayan küresel çağda öğrenmeyi bilen, çok boyutlu ve yaratıcı düşünme becerilerine sahip, aktif bireylerden oluşan bir toplum inşa etmek eğitimin hedefi haline gelmiştir (Balay, 2004). 21. Yüzyılda ise ABD, Kanada, Japonya gibi ülkeler ve bazı Avrupa Ülkeleri merkezi sistem dışında kalan alternatif eğitim yaklaşımlarının uygulanmasına imkân tanıyarak bireylerin istedikleri eğitim modeli ile eğitim almasına olanak tanımışlardır (Gündüz, 2013). Böylelikle alternatif eğitim 
yaklaşımları hem tanınırlık hem de uygulanabilirlik açısından yaygınlık kazanmaya başlamıştır.

Alternatif eğitim en genel anlamıyla; kamu sisteminin parçası olan, ana akım eğitimin dışında kalan ve öğrenene farklı öğrenme yaşantıları sunan birey odaklı bir eğitim yaklaşımıdır (Kaya ve Gündüz, 2015; Memduhoğlu, Mazlum ve Alav, 2015). Birçok farklı alternatif eğitim yaklaşımı bulunmakla birlikte Türkiye' de özellikle okul öncesi eğitim açısından Montessori ve Waldorf Yaklaşımlarının daha fazla yaygınlık kazandığ1 görülmektedir. Öğrenciyi merkeze alan bu iki yaklaşımın kendilerine has felsefeleri, öğretim metot ve materyalleri bulunmaktadır.

Waldorf eğitimi yaklaşımı fikri ilk olarak Rudolf Steiner'ın 1919 yılında Almanya'nın Stuttgart kentinde Waldorf- Astoria fabrikasında çalışan işçilere verdiği bir konferansta ortaya atılmıştır (Paull, 2011). Steiner eğitimin bir çıkmaza girdiğini, modern dünyanın yeni bir toplum inşası için yenilikçi bir eğitim sistemine ihtiyaç duyduğunu ifade etmiş ve fabrika sahibi Emil Molt'un desteği ile ilk Waldorf okulunu kurmuştur (Uhrmacher, 1995; Merkle- Yeşilda ̆̆ ve Yeşildağ, 2018). Bugün 66 ülkede 1182 Waldorf ve Rudolf Steiner okulu ve 69'dan fazla ülkede 1911 Waldorf Anaokulu bulunmaktadır (Waldorf World List, 2019).

Ayrım gözetmeksizin her çocuğun eşit imkanlardan faydalanmasını öngören Waldorf yaklaşımında eğitim doğayla uyumlu ve iç içe olmalı ve öğrenciye kendi hızına göre ilerleme imkânı verilmelidir. Eğitim yaklaşımı değerlendirmeye farklı bir boyut kazandırmış olup küçük sınıflarda öğrencilere karne veya not verilmez. Lise döneminden itibaren verilen notlar ve karnelerdeki amaç öğrencinin kendi gelişiminden haberdar olması ve motivasyonunun artırılmasıdır (Kotaman, 2009). Waldorf yaklaşımı çocuk merkezlidir ve temelde çocuğun duygusal ve sosyal gelişimini desteklemeyi amaç edinir (Çelik, 2013). Ayrıca, çocuğun çok yönlü gelişimi de sağlanmalıdır ve Waldorf yaklaşımında bu alanlar; akıl, kalp, yetenek olarak ifade edilmektedir (Akdağ, 2006; Edwards, 2002). Çocuklar rekabetin olmadı ğı, kendilerini özgürce ifade edebilecekleri bir ortamda eğitim almalıdır. Teknolojik cihazlara sınıf ortamında mümkün olduğunca yer verilmemeli, çocuklar doğal malzemeleri kullanarak yeni şeyler öğrenmeli ve içinde yaşadıkları dünyayı keşfetmelidir. Yaklaşımın bir diğer önemli özelliği ise öğrenenlerin sanatsal gelişimini ön planda tutmasidir.

Waldorf yaklaşımına ilişkin yapılan alanyazın taramasında Türkiye'de yapılan çalışmaların genellikle derleme türünde olduğu ve sınırlı sayıda araştırma olduğu görülmüştür (Bayhan ve Bencik, 2008; Çelik, 2013; Kaya ve Gündüz, 2015; Kotaman, 2009). Bu araştırmanın amac1, okul öncesi dönemde alternatif bir eğitim modeli olan Waldorf yaklaşımı ve materyallerine yönelik olarak okul öncesi öğretmenlerinin görüşlerini incelemektir. Yaşadığımız bilgi çağında farklı öğrenme ortamlarının desteklenmesi eğitim sistemleri açısından bir gereklilik haline gelmiş olup dünya çapında yaygınlık kazanan Waldorf yaklaşımının incelenmesinin mevcut durumun betimlenmesi ve alanyazına buna benzer çalışmaların kazandırılması açısından katkı sağlayacağı düşünülmektedir.

\section{Yöntem}

$\mathrm{Bu}$ araştırma nitel araştırma yöntemlerinden olgubilim desenine göre tasarlanmıştır. Olgubilim deseni; var olan olaylar, algılar, durumlar, deneyimler, yönelimler ve kavramlar ile ilgili ayrıntılı bilgi toplamayı amaçlayan bir araştırma desenidir 
(Yıldırım ve Şimşek, 2013). Bu araştırmada ise okul öncesi dönemde alternatif bir eğitim modeli olan Waldorf yaklaşımı ve materyallerine yönelik olarak okul öncesi öğretmenlerinin görüşlerini incelemek amacıyla olgubilim deseninden yararlanılmıştır.

\section{Katılımcilar}

Araştırmanın katılımcıları belirlenirken olasılıksız örnekleme yöntemlerinden amaçlı örnekleme tekniği kullanılmıştır. Nitel araştırmalarda sıklıkla kullanılan amaçlı örnekleme ile araştırmanın amacına uygun olan tipik grup veya gruplar seçilerek bu gruplar üzerinde araştırma yürütülmektedir (Balc1, 2013). Bu araştırmanın katılımc1 grubu ise Waldorf materyal sergisine katılan okul öncesi öğretmenleri arasından seçilmiştir. Sergiye katılan öğretmenlere araştırma hakkında bilgi verilmiş ve gönüllülük esasına göre araştırmaya dahil olmayı kabul eden 8 öğretmen araştırmanın katılımcı grubu olarak belirlenmiştir. Araştırmada etik ilkeleri korumak adına öğretmenlerin gerçek isimleri gizlenerek $\ddot{\mathrm{O}}_{1}, \ddot{\mathrm{O}}_{2}, \ddot{\mathrm{O}}_{3}, \ddot{\mathrm{O}}_{4}, \ddot{\mathrm{O}}_{5}, \ddot{\mathrm{O}}_{6}, \ddot{\mathrm{O}}_{7}$ ve Ö 8 şeklinde kodlanmıştır. Katılımcı öğretmenlerin özellikleri Tablo 1'de sunulmaktadır.

Tablo 1

Katılımoı Öğretmenlerin Özellikleri

\begin{tabular}{|c|c|c|c|c|}
\hline Katılımcı & Yaş & Cinsiyet & $\begin{array}{l}\text { Mesleki } \\
\text { Tecrübe }\end{array}$ & Mezun Olunan Üniversite \\
\hline$\ddot{\mathrm{O}}_{1}$ & 39 & Kadın & $17 Y_{11}$ & $\begin{array}{l}\text { Anadolu Üniversitesi Açık Öğretim Fakültesi- Okul Öncesi } \\
\text { Öğretmenliği }\end{array}$ \\
\hline$\ddot{\mathrm{O}}_{2}$ & 47 & Kadın & $25 Y_{1}$ & $\begin{array}{l}\text { Gazi Üniversitesi Mesleki Gelişim Fakültesi- Çocuk } \\
\text { Gelişimi Bölümü }\end{array}$ \\
\hline$\ddot{\mathrm{O}}_{3}$ & 33 & Kadın & $11 Y_{1}$ & $\begin{array}{l}\text { Sivas Cumhuriyet Üniversitesi Eğitim Fakültesi- Okul } \\
\text { Öncesi Öğretmenliği Bölümü }\end{array}$ \\
\hline $\mathrm{O}_{4}$ & 49 & Kadın & $29 Y_{1}$ & $\begin{array}{l}\text { Gazi Üniversitesi Mesleki Gelişim Fakültesi- Çocuk } \\
\text { Gelişimi Bölümü }\end{array}$ \\
\hline $\mathrm{O}_{5}$ & 42 & Kadın & $16 Y_{1}$ & $\begin{array}{l}\text { Anadolu Üniversitesi Açık Öğretim Fakültesi Okul Öncesi } \\
\text { Öğretmenliği }\end{array}$ \\
\hline$\ddot{\mathrm{O}}_{6}$ & 35 & Kadın & $14 Y_{1} 1$ & $\begin{array}{l}\text { Sivas Cumhuriyet Üniversitesi Eğitim Fakültesi- Okul } \\
\text { Öncesi Öğretmenliği Bölümü }\end{array}$ \\
\hline$\ddot{\mathrm{O}}_{7}$ & 40 & Kadın & $19 Y_{1}$ & $\begin{array}{l}\text { Gazi Üniversitesi Kırşehir Eğitim Fakültesi- Okul Öncesi } \\
\text { Öğretmenliği }\end{array}$ \\
\hline $\mathrm{O}_{8}$ & 36 & Kadın & $13 Y_{1}$ & $\begin{array}{l}\text { Anadolu Üniversitesi Açık Öğretim Fakültesi- Okul Öncesi } \\
\text { Öğretmenliği }\end{array}$ \\
\hline
\end{tabular}

Tablo 1 incelendiğinde tamamı kadın olan katılımcı öğretmenlerin yaşlarının 33- 49 arasında olduğu ve mesleki tecrübelerinin 11 yıldan 29 yıla kadar değişmekte olduğu görülmektedir.

\section{Veri Toplama Araçları}

Araştırmada veri toplamak amacıyla nitel araştırmalarda sıklıkla kullanılan görüşme yönteminden yararlanılmıştır. Görüşme önceden belirlenen bir amaç doğrultusunda kaynak kişi veya kişilerin bir olay, olgu veya duruma ilişkin duygu, düşünce ve bilgilerini almak için kullanılan bir yöntemdir (Balc1, 2013; Patton, 2014). Veri toplama sürecinde araştırmanın katılımcısı konumundaki okul öncesi öğretmenlerinin Waldorf 
yaklaşımı ve materyallerine yönelik görüşlerini almak amacıyla "öğretmen görüşme formu" kullanılmıştır.

Öğretmen görüşme formu. Araştırmada kullanılan öğretmen görüşme formu araştırmacı tarafından geliştirilmiştir. Öğretmen görüşme formu hazırlanırken öncelikle alan yazın taraması yapılarak olası görüşme soruları yazılmıştır. Görüşme formunun kapsam geçerliliğini sağlamak amacıyla bir ölçme değerlendirme, bir eğitim programları ve öğretimi ve bir okul öncesi eğitimi alan uzmanının uzman görüşüne başvurulmuştur. Uzmanlardan alınan dönütler doğrultusunda gerekli görülen düzeltmeler yapılmıştır. Ayrıca formun görünüş geçerliliğini test etmek amacıyla araştırmanın katılımcılarıyla benzer özellik taşıyan bir okul öncesi öğretmeni ile pilot çalışma yapılmıştır. Pilot çalışma sonucunda formda bulunan bazı ifadelerde düzenlemeler yapılarak forma son hali verilmiştir.

Öğretmen görüşme formu on maddeden ve sonda sorularından oluşmaktadır. Görüşme formunda okul öncesi öğretmenleri açısından; Waldorf yaklaşımının olumlu, olumsuz yanlarını belirlemeye, yaklaşımın Türkiye'deki okullarda uygulanabilirliğine, Waldorf materyallerinin öğretim sirasında kullanımının avantajlarını, dezavantajlarını belirlemeye ve sınıf ortamında uygulanabilirliğine yönelik sorular bulunmaktadır.

\section{Veri Toplama Süreci}

Okul öncesi öğretmenlerinin Waldorf yaklaşımı ve materyallerine yönelik görüşlerini belirlemek amacıyla 2019-2020 eğitim- öğretim yılında Sivas Cumhuriyet Üniversitesi Eğitim Fakültesi sergi salonunda çeşitli Waldorf materyallerinin sunulduğu bir sergi düzenlenmiştir. Sergide sunulan materyaller araştırmacı tarafından hazırlanmış olup ayrıca Waldorf yaklaşımını tanıtıcı ve bilgi verici posterler tasarlanmıştır. Sergide kullanılan Waldorf Materyallerinden örnekler ve posterler Şekil 1'de sunulmaktadır.
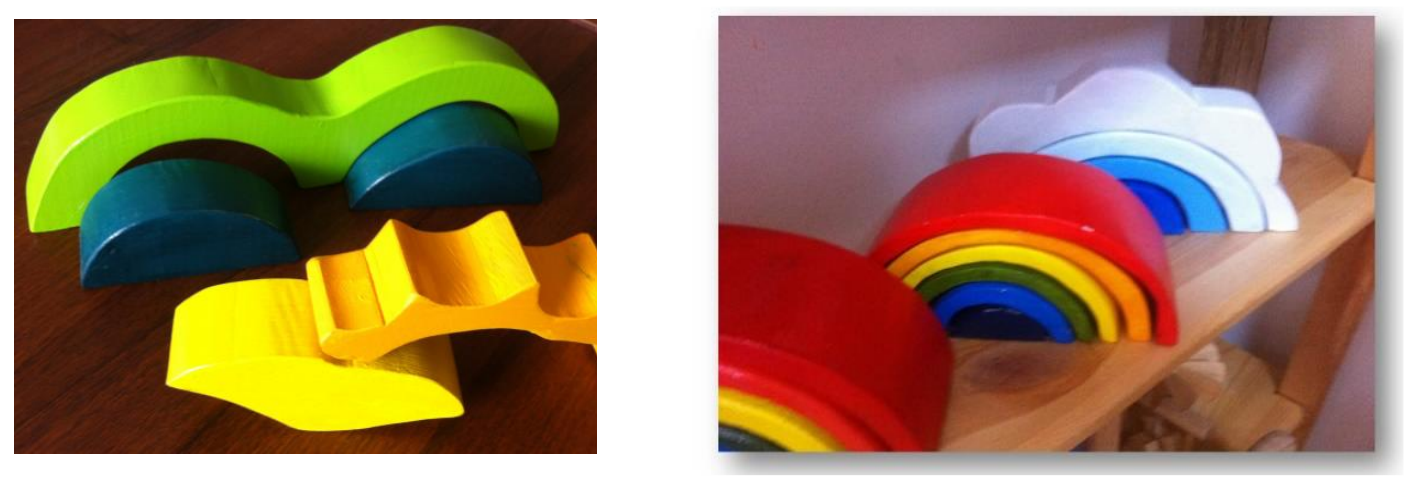

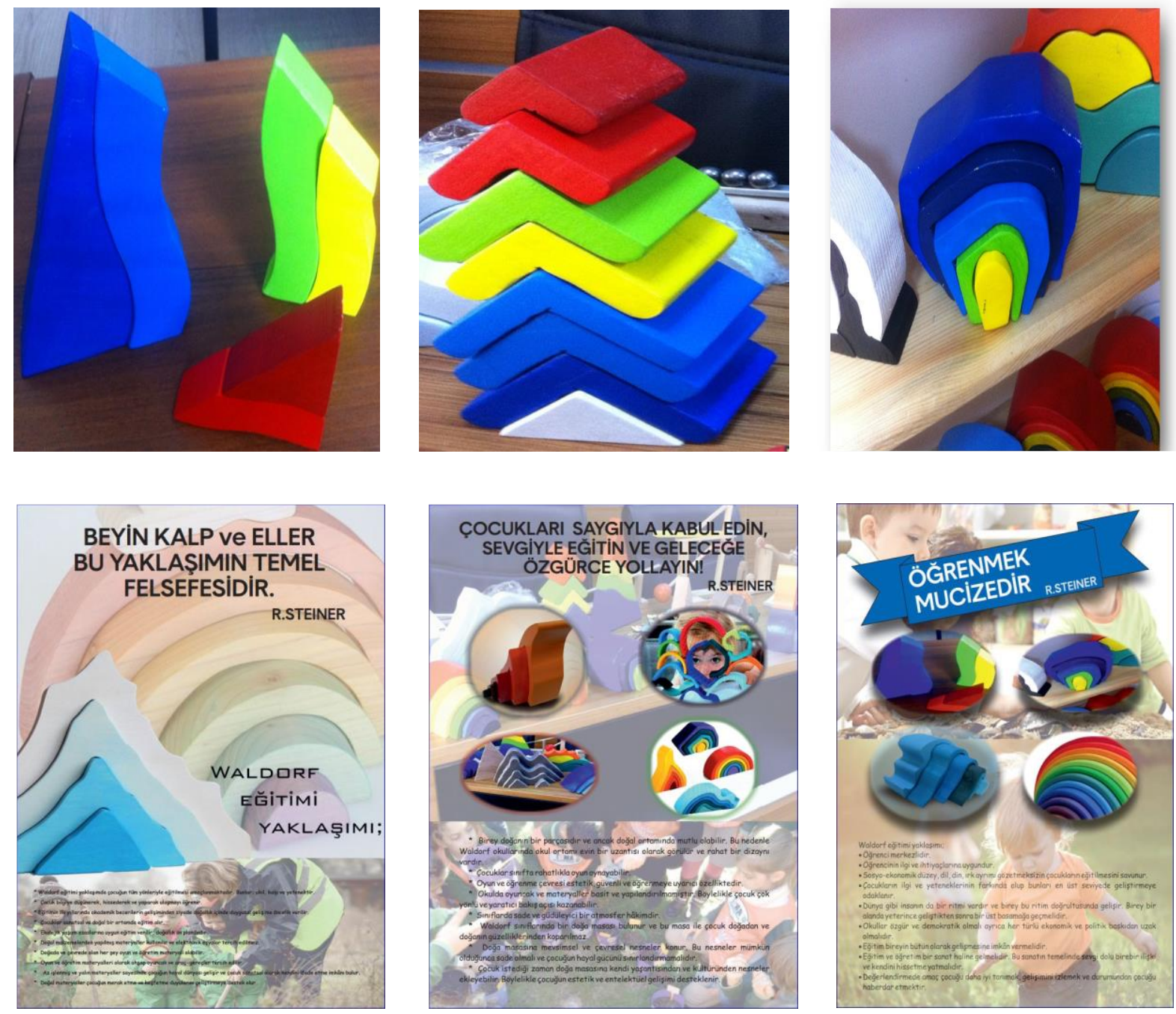

Şekil 1. Örnek Waldorf materyalleri ve posterler

Sergi süresince araştırmacılar okul öncesi öğretmenlerinin sorularını yanıtlamış ve materyallere yönelik rehberlik hizmeti sunmuştur. Serginin tamamlanmasının ardından araştırmaya katılmaya gönüllü öğretmenlere araştırmacı tarafından geliştirilen görüşme formu sunularak doldurmaları istenmiştir. Öğretmenler görüşme formunu doldururken araştırmacı tarafından herhangi bir müdahalede bulunulmamış ve süre kısıtlaması yapılmamıştır.

\section{Verilerin Analizi}

$\mathrm{Bu}$ araştırmada nitel veri analiz yöntemlerinden betimsel analiz kullanılmıştır. Betimsel analizde araştırma verilerine bağlı kalınarak bulgular betimsel olarak sunulmaktadır (Yıldırım ve Şimşek, 2013; Glesne, 2012). Araştırmadan elde edilen verilerin analizinde ise MAXQDA 20 nitel veri analizi programı kullanılmıştır. Veri analizinde katılımcıların birbirine benzer ifadeleri gruplanarak yorumlanmış, tablolar ve kod haritaları eşliğinde sunulmuştur. Ayrıca araştırma sonuçlarının geçerliliğine katkı sağlamak amacıyla katılımcı ifadelerinden örnekler seçilerek direk alıntılara yer verilmiştir. 


\section{Bulgular}

Okul öncesi dönemde alternatif bir eğitim modeli olan Waldorf yaklaşımı ve materyallerine yönelik olarak okul öncesi öğretmenlerinin görüşlerini incelemek amacıyla gerçekleştirilen bu araştırmada bulgular; "Waldorf Yaklaşımına İlişkin Görüşler" ve "Waldorf Materyallerine İlişkin Görüşler" başlıkları altında sunulmaktadir.

\section{Waldorf Yaklaşımına İlişkin Görüşler}

Araştırma kapsamında katılımcı öğretmenlerle yapılan görüşmelerden elde edilen bulgulara göre okul öncesi öğretmenleri Waldorf, Montessori ve Reggio Emilia alternatif eğitim yaklaşımları hakkında bilgiye sahiptir (Tablo 2).

Tablo 2

Okul Öncesi Öğretmenlerinin Bilgi Sahibi Olduklarn Alternatif Ĕğitim Yaklaşımları

\begin{tabular}{lll}
\hline Alternatif Eğitim Yaklaşımı & f & Katılımc1 \\
\hline Waldorf Eğitim Yaklaşımı & 7 & $\ddot{\mathrm{O}}_{1}, \ddot{\mathrm{O}}_{2}, \ddot{\mathrm{O}}_{3}, \ddot{\mathrm{O}}_{4}, \ddot{\mathrm{O}}_{5}, \ddot{\mathrm{O}}_{6}, \ddot{\mathrm{O}}_{7}$ \\
Montessori Eğitim Yaklaşımı & 7 & $\ddot{\mathrm{O}}_{1}, \ddot{\mathrm{O}}_{2}, \ddot{\mathrm{O}}_{3}, \ddot{\mathrm{O}}_{4}, \ddot{\mathrm{O}}_{6}, \ddot{\mathrm{O}}_{7}, \mathrm{O}_{8}$ \\
Reggio Emilia Eğitim Yaklaşımı & 3 & $\ddot{\mathrm{O}}_{1}, \ddot{\mathrm{O}}_{3}, \ddot{\mathrm{O}}_{6}$ \\
\hline
\end{tabular}

Katılımcı öğretmenlerin çoğunluğu Waldorf yaklaşımı ile ilgili çeşitli bilgilere sahip olduklarını ifade etmekle birlikte $\ddot{O}_{8}$ bu yaklaşımla ilgili uygulama yapmaya yetecek kadar bilgi sahibi olmadığını ifade etmiştir. Okul öncesi öğretmenlerinin Waldorf eğitim yaklaşımına yönelik bilgi kaynakları ise Tablo 3' de sunulmaktadır.

Tablo 3

Okul Öncesi Öğretmenlerinin Waldorf Ĕ̆itim Yaklaşımına Yönelik Bilgi Kaynakları

\begin{tabular}{lll}
\hline Bilgi Kaynakları & f & Katılımc1 \\
\hline İnternet Siteleri & 6 & $\ddot{\mathrm{O}}_{1}, \ddot{\mathrm{O}}_{2}, \ddot{\mathrm{O}}_{3}, \ddot{\mathrm{O}}_{4}, \ddot{\mathrm{O}}_{6}, \ddot{\mathrm{O}}_{7}$ \\
Lisans Eğitiminde Alından Dersler & 4 & $\ddot{\mathrm{O}}_{2,}, \ddot{\mathrm{O}}_{4}, \ddot{\mathrm{O}}_{5}$ \\
Kitaplar & 2 & $\mathrm{O}_{6}, \mathrm{O}_{7}$ \\
Diğer Meslektaşlar & 1 & $\mathrm{O}_{2}$ \\
\hline
\end{tabular}

Tablo 3 incelendiğinde öğretmenlerin en fazla sıklıkla internet kaynaklarından en az sıklıkla ise diğer meslektaşlardan bilgi edindiği görülmektedir. Öğretmenler lisans döneminde aldıkları dersleri ve bireysel araştırmaları sonucunda edindikleri kitapları da bilgi kaynağı olarak belirtmişlerdir.

Yakın zamanda okuduğum kitapta alternatif eğitim yaklaşımlarını ele almıştı. $\mathrm{O}$

dönemde internetten de araştırarak birkaç makale okumuştum. ( $\left.\ddot{O}_{6}\right)$

Araştırmaya katılan öğretmenlerin tamamı Waldorf eğitim yaklaşımının okul öncesi eğitim açısından olumlu özelliklerinin olduğunu ve bu yaklaşımı diğer meslektaşlarına da tavsiye edebileceklerini ifade etmiştir. Öğretmenler Waldorf yaklaşımının yaratıcı düşünme, bilimsel düşünme, kendini ifade etme ve yeni durumlara uyum sağlama açısından yararları olduğunu belirtmiştir. Öğretmen ifadelerine göre yaklaşımın en olumlu yanlarından biri ise çocuğun bireysel ilerlemesine katkı sağlaması ve bireysel farklılıkları dikkate alması şeklindedir.

Eğitimi sanata çevirmeyi amaç edinen, bütünden parçaya inen bir yaklaşımdır.

Çocukların bireyselliğini, farklılı̆̆ını ve özgüvenini ortaya çıkarmasında çok etkili 
bir yaklaşım olduğunu düşünüyorum. Ayrıca uygulaması kolay bir yöntemdir.

$\left(\ddot{O}_{7}\right)$

Ayrıca yaklaşımın doğayla uyumlu olması ve sanatsal faaliyetleri barındırması da yaklaşımın bir diğer olumlu özelliği olarak ön plana çıkmaktadır.

Doğadan doğal materyaller kullanılması, çocukların sanatsal etkinliklerle öğrenmesini desteklemesi, bireysel ilerlemeyi dikkate alması. Bireysel ilerlemenin çok esnek olması, geniş zamana yayılabilmesi olarak hatırlıyorum. (Ö)

Katılımcı öğretmenlerden biri ise yaklaşımın olumlu özelliklerinin olduğunu ancak Türk Eğitim Sistemi'nde uygulanmasının bazı güçlükler yaratabileceğini belirtmiştir.

Waldorf çocukların yaratıcı düşünme becerisi üzerine yoğunlaşan, çocukların özgür ve bağımsız bir kişilik geliştirmesini, kendini bulup keşfetmesine yardımcı olan; özellikle sanat çalışmalarıyla, müzik, günlük yaşam becerilerini geliştirmek üzere yoğunlaşan, doğal ve sade materyallerle oluşan bir eğitim felsefesi... Ancak çok fazla bilinmeyen bir eğitim felsefesi okul öncesi ve ilkokulun sarmal bir şekilde birbirini desteklemesi gerekiyor. Şu anda ülkemizde uygulanan eğitim sistemimizle çok fazla uyuşmuyor, algıların kırılması zor olabilir. Rekabet, not sistemi ve değerlendirme olmayışı, teknolojik araçların kullanılmaması nedeniyle uygulanabilir bulmuyorum. (Ö)

\section{Waldorf Materyallerine İlişkin Görüşler}

Araştırma kapsamında katılımcı öğretmenlerin görüşlerine göre Waldorf materyallerinin kullanımın avantajları ve dezavantajları incelenmiştir. Öğretmen görüşlerine göre Waldorf materyallerinin avantajları; öğrencinin yaratıcı düşünme becerilerine katkı sağlaması, ilgi çekici olması, kullanım kolaylığı, materyalin birden çok amaca hizmet etmesi, etkili öğretim ve motivasyon sağlaması şeklindedir. Materyallerin dezavantajlarına yönelik öğretmen görüşleri ise tanınırlı̆̆ın az olması ve maliyetli olmasıdır. Waldorf yaklaşımı materyallerinin öğretmen görüşlerine göre avantaj ve dezavantajları Şekil 2'de sunulmaktadır.

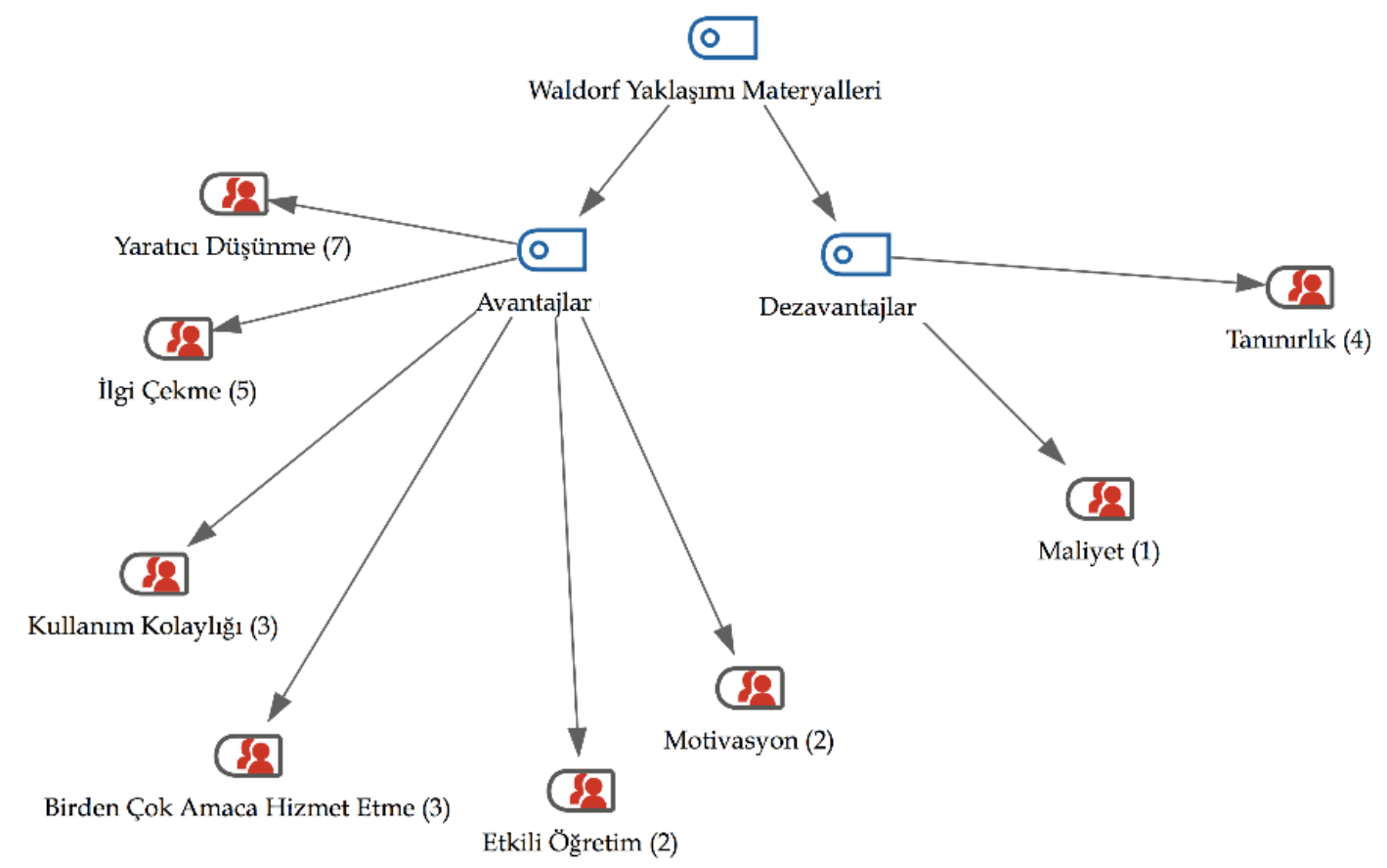

Şekil 2. Waldorf yaklaşımı materyallerinin avantaj ve dezavantajları kod haritası 
Araştırmaya katılan öğretmenler en fazla sıklıkla Waldorf Materyallerinin öğrencinin yaratıcı düşünme becerilerine katkı sağlayacağı yönünde görüş bildirmiştir. En az sıklıkla ise etkili öğretim ve motivasyon sağlama yönünde katkıları olduğu yönündedir (Tablo 4).

Tablo 4

Waldorf Yaklaşımı Materyallerinin Avantajları

\begin{tabular}{lll}
\hline Avantajlar & f & Kat1lımc1 \\
\hline Yaratıc1 Düşünme & 6 & $\ddot{\mathrm{O}}_{1}, \ddot{\mathrm{O}}_{2}, \ddot{\mathrm{O}}_{4}, \ddot{\mathrm{O}}_{5}, \ddot{\mathrm{O}}_{6}, \ddot{\mathrm{O}}_{8}$ \\
İlgi Çekme & 5 & $\ddot{\mathrm{O}}_{1}, \mathrm{O}_{2}, \mathrm{O}_{3}, \mathrm{O}_{7}, \mathrm{O}_{8}$ \\
Kullanım Kolayllı̆g1 & 3 & $\ddot{\mathrm{O}}_{2}, \ddot{\mathrm{O}}_{3}, \ddot{\mathrm{O}}_{4}$ \\
Birden Çok Amaca Hizmet Etme & 3 & $\ddot{\mathrm{O}}_{3}, \ddot{\mathrm{O}}_{4}, \ddot{\mathrm{O}}_{5}$ \\
Etkili Öğretim & 2 & $\mathrm{O}_{2}, \mathrm{O}_{6}$ \\
Motivasyon & 2 & $\ddot{\mathrm{O}}_{1}, \ddot{\mathrm{O}}_{4}$ \\
\hline
\end{tabular}

Öğretmenler, materyallerin farklı şekillerde kullanılabilir ve doğal malzemelerden yapılmış olmasından dolayı öğrencilerin farklı şekillerde düşünme yetilerinin destekleneceği ve yaratıcı düşünme becerilerinin gelişeceğini ifade etmiştir. Materyallerin okul öncesi dönem çocukları açısından ilgi çekici olması da bir diğer olumlu özellik olarak değerlendirilmiştir.

Materyallerin sınıftaki çocukların ilgisini çekeceğini ve onların bilimsel düşünme

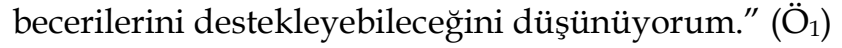

Çocuğun yaratıcılığı desteklenerek çok yönlü gelişimi desteklenir diye düşünüyorum. $\left(\ddot{O}_{4}\right)$

$\ddot{O}_{5}$ ise materyallerin kullanımında eğitimcinin rolüne değinerek öğretmenlerin öğrenciyi doğru şekilde rehberlik etmesi gerektiğini ve yeniliklere açık olması gerektiğini vurgulamıştır.

Özellikle bu tip materyalleri kullanırken eğitimcinin çocukları doğru bir şekilde yönlendirmesi, kendine özgü ürünler ortaya koyabilmelerine olanak sağlaması gerekiyor. Bunun için önce kendi düşünce biçimini değiştirip yeniliklere açık olmasi gerekiyor. $\left(\ddot{O}_{5}\right)$

Katılımcı öğretmenler, Waldorf yaklaşımı materyallerinin tanınırlık ve maliyet açısından dezavantajları olduğu yönünde görüş bildirmiştir (Tablo 5).

Tablo 5

Waldorf Yaklaşımı Materyallerinin Dezavantajlan

\begin{tabular}{lll}
\hline Dezavantajlar & f & Katılımc1 \\
\hline Tanınırlık & 4 & $\ddot{\mathrm{O}}_{2,} \ddot{\mathrm{O}}_{3}, \ddot{\mathrm{O}}_{5}, \ddot{\mathrm{O}}_{7}$ \\
Maliyet & 1 & $\mathrm{O}_{2}$ \\
\hline
\end{tabular}

Katılımcı öğretmenler, Waldorf yaklaşımının ve materyallerinin Türkiye'de yeterince bilinmediğinden dolayı özellikle veliler açısından güçlüklerle karşılaşılabileceğini ifade etmiştir. Ayrıca, öğretmenlerin de bu konuda yeterince bilgi sahibi olmadıklarını ve eğitime ihtiyaç duydukları görüşündedirler.

Uygulama öncesinde eğitimciler bir eğitimden geçirilebilir. $\left(\ddot{\mathrm{O}}_{1}\right)$

$\mathrm{Bu}$ anlamda eğitim almamız gerektiğini düşünüyorum. $\left(\mathrm{O}_{3}\right)$

Katılımcı öğretmenler, Waldorf materyallerinin dersi daha eğlenceli hale getireceğini, serbest zaman ve oyun etkinliklerinin yanı sıra birçok becerinin 
öğretiminde kullanılabilir olduğunu ifade etmekle birlikte daha önce Waldorf materyallerinin kullanma imkânlarının olmadığını belirtmiştir. Ayrıca, okul öncesi öğretmenlerin tamamı Waldorf yaklaşımı materyallerini derslerinde kullanmak istediklerini belirtmiştir. Öğretmen ifadelerine göre Waldorf yaklaşımı materyallerini öğrencinin bilişsel gelişim, dil gelişimi, sosyal duygusal gelişim ve motor gelişim açısından kullanmayı tercih edebilecekleri öğrenme alanları Şekil 3'de sunulmaktadır.

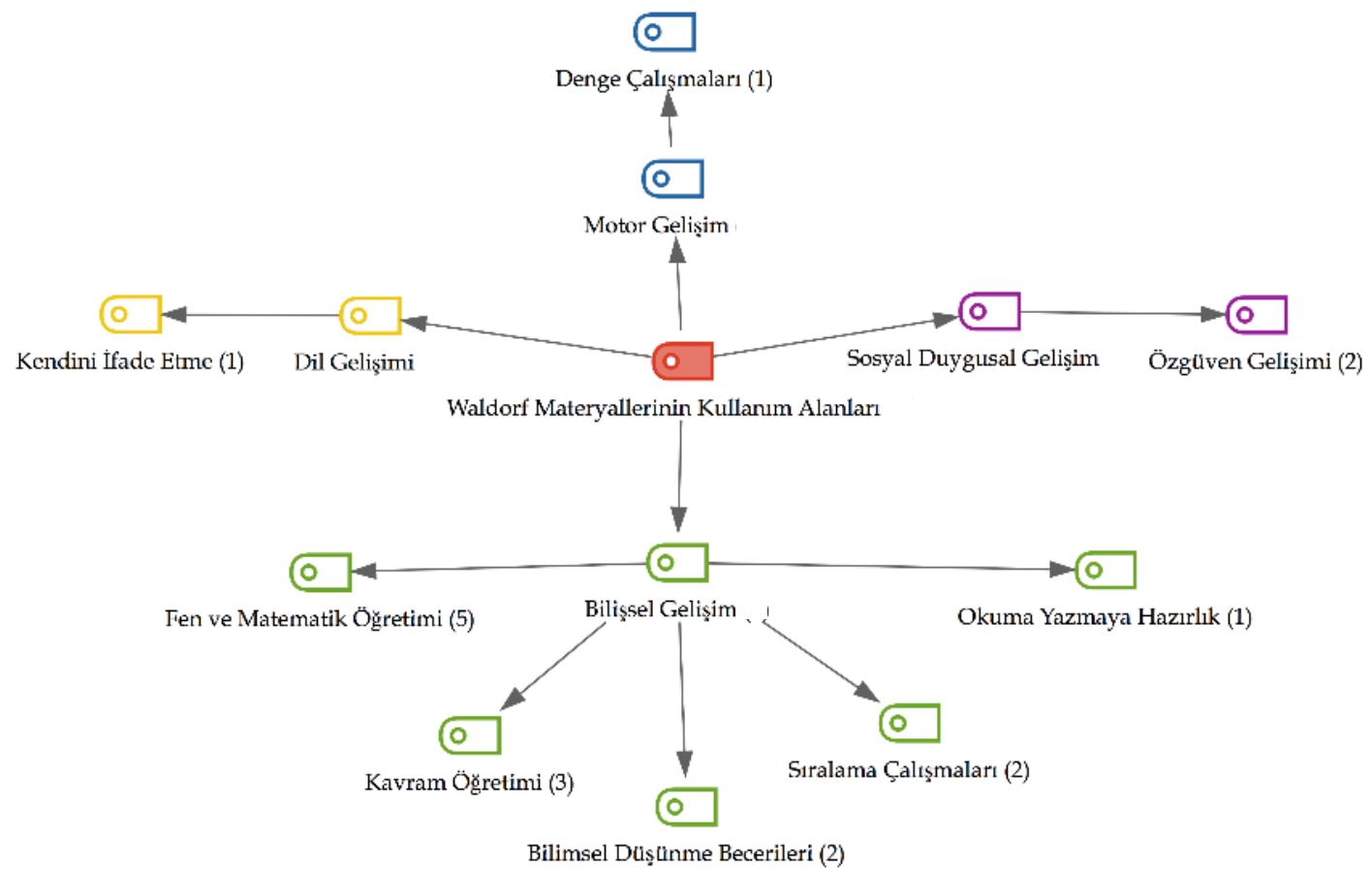

Şekil 3. Waldorf yaklaşımı materyallerinin kullanım alanları kod haritası

Araştırmaya katılan öğretmenlerden elde edilen bulgulara göre Waldorf materyalleri motor gelişim -denge çalışmaları-, dil gelişimi -kendini ifade etme- ve sosyal duygusal gelişim -özgüven gelişimi- alanlarında kullanılabilir olmakla birlikte en fazla sıklıkla bilişsel gelişim alanında kullanılabilir. Öğretmenler bilişsel gelişim alanında; fen ve matematik öğretimi, kavram öğretimi, bilimsel düşünme becerilerinin öğretimi, sıralama çalışmaları ve okuma yazmaya hazırlık çalışmaları sırasında materyalleri kullanabileceklerini ifade etmiştir.

Materyalin dokusu, sadeliği, birçok şekil oluşturulabilir olması, bilimsel düşünme becerilerini geliştirecektir. Denge materyalleri, matematik ve fen öğretimine pozitif katkı sağlar örneğin gelecek için moment-denge kavramlarını öğretmemizi sağlar. $\left(\ddot{\mathrm{O}}_{3}\right)$

Gördüğüm materyaller çocuklarda parça bütün, mekânda konum, sayı, renk, şekil, örüntü oluşturma ve özgün bir şekilde çocukların kendi hikayelerini oluşturabilecekleri etkinliklerde kullanabileceğimi düşünüyorum. (Ö 5$)$

\section{Tartışma, Sonuç ve Öneriler}

Araştırmadan elde edilen bulgulara göre okul öncesi öğretmenleri alternatif eğitim yaklaşımlarından Waldorf, Montessori ve Reggio Emilia eğitim yaklaşımları hakkında bilgi sahibidir. Kılınç, Karayel ve Koyuncu (2018)'ya göre Türkiye'de okul öncesi öğretmenleri açısından en bilinen alternatif eğitim yaklaşımları Montessori Yaklaşımı 
ve devamında Reggio Emilia, High Scope, Waldorf Yaklaşımlarıdır. Bu çalışma araştırma bulgularını destekler niteliktedir. Öğretmenlerin Waldorf yaklaşımına ilişkin bilgi kaynakları ise en fazla sıklıkla internet siteleri ve lisans eğitiminde aldıkları dersler iken en az sıklıkla ise kitaplar ve diğer meslektaşlardır.

Araştırma bulgularına göre öğretmenler okul öncesi dönemde Waldorf yaklaşımını faydalı bulmaktadır. Ayrıca, bu yaklaşımı diğer meslektaşlarına da tavsiye edeceklerini belirtmiştir. Öğretmen görüşlerinden hareketle yaklaşımın olumlu yanları yaratıcı düşünme, bilimsel düşünme, kendini ifade etme, yeni durumlara uyum sağlama, çocuğun bireysel ilerlemesine katkı sağlama ve bireysel farklılıkları dikkate alma, doğayla uyumlu olma ve sanatsal faaliyetleri barındırma şeklindedir. Koca ve Ünal (2018)'ın araştırmalarından elde ettikleri sonuca göre öğretmenler Waldorf anaokullarının misyonunu doğayla iç içe verilen eğitim ve kendine güvenen bireyler yetiştirmek olarak ifade etmektedir. Waldorf yaklaşımının temelinde bulunan bahsi geçen özellikler, bu araştırmanın bulgularıyla benzerlik göstermektedir.

Öğretmenler, olumsuz bir durum olarak yaklaşımın Türk eğitim sisteminde uygulanabilirliği açısından bazı güçlükler yaşanabileceği görüşünü dile getirmiştir. Bu durumun nedeni Türk Eğitim Sistemi'nde alternatif yaklaşımların çok fazla yer edinememiş olması olabilir. Waldorf yaklaşımının Türkiye' de henüz yeterince etkin kullanılmadığı bilinmektedir. Örneğin, yaklaşımın ortaya çıktı̆̆ı ülke olarak bilinen Almanya'da 563 Waldorf anaokulu bulunmakta iken; Hollanda'da 79, İsveç'de 75, Danimarka'da 66, Macaristan'da 56, Norveç'de 53, İsviçre' de 50, İngiltere' de 40, İtalya' da 38, Finlandiya' da 41, Rusya' da 35, Fransa'da 21 ve İspanya'da 19 Waldorf anaokulu bulunmaktadır (Waldorf World List, 2019). Türkiye' de ise yanızca 2 Waldorf anaokulu bulunmaktadır. Ancak tümüyle Waldorf yaklaşımı açısından dizayn edilmemiş olmakla birlikte yaklaşımın kullanıldığı farkı okullar ve sınıflar olduğu bilinmektedir. Almanya'da ortaya çıkan bu yaklaşımın temel özeliklerine bağlı kalınarak Türk Eğitim Sistemi' ne adapte edilebileceği düşünülmektedir.

Araştırma kapsamında Waldorf materyallerinin tanıtıldığı sergiye katılan okul öncesi öğretmenleri Waldorf materyallerinden örnekleri incelemiştir. Öğretmenlerin materyallere ilişkin olumlu görüşleri öğrencinin yaratıcı düşünme becerilerine katkı sağlaması, ilgi çekici olması, kullanım kolaylığı, materyalin birden çok amaca hizmet etmesi, etkili öğretim ve motivasyon sağlaması şeklindedir. Materyallerin tanınırlığının yetersiz olması ve maliyetli olması ise olumsuz görüşler olarak karşımıza çıkmaktadır.

Bir diğer önemli bulgu ise materyallerin kullanımı sırasında öğretmenin rolüne ilişkindir. Öğretmen, yeniliklere açık bir tutum içinde olmalı ve ders esnasında öğrencileri doğru yönlendirmelidir. Öğretmenlerin genel görüşü kendilerinin yetersiz bilgi sahibi oldukları ve eğitime ihtiyaç duydukları yönündedir. Benzer şekilde Kılınç, Karayel ve Koyuncu (2018) alternatif eğitim yaklaşımlarına ilişkin yaptıkları araştırmada öğretmenlerin genel olarak bilgi gereksinimleri olduğu sonucuna ulaşmıştır. Waldorf yaklaşımını uygulayabilmek için öğretmenlerin özel olarak eğitim almaları gerekmektedir (Rawson, 2010).

Öğretmenler Waldorf materyallerinin bilişsel gelişim, dil gelişimi, motor gelişim ve sosyal duygusal gelişim alanlarında kullanılabilir olduğunu ifade etmekle birlikte en fazla sıklıkla bilişsel gelişim alanında bulunan kazanımların öğretiminde 
yararlanabileceklerini belirtmiştir. Araştırma bulgularına göre; bilişsel gelişim alanında fen ve matematik öğretimi, kavram öğretimi, bilimsel düşünme becerilerinin öğretimi, sıralama çalışmaları ve okuma yazmaya hazırlık çalışmaları sırasında; motor gelişim alanında denge çalışmaları, dil gelişimi alanında kendini ifade etme becerileri ve sosyal duygusal gelişim alanında özgüven gelişimi açısından materyallerden faydalanılabilir. Steiner (1996), Waldorf yaklaşımının birçok farklı gelişim alanında kullanılabileceğini ve yaklaşımın temel amaçlarının birinin de bireyin çok yönlü gelişimine katkı sağlamak olduğunu ifade etmektedir.

Küresel çapta yaşanan değişimler, eğitim sistemi ile doğrudan ilişkilidir. Çağın gerekliliklerini yakalayabilmek adına içinde bulunulan döneme uygun özelliklerde bireylerin yetiştirilmesi eğitim sistemlerinin önemli işlevleri arasındadır. Okul öncesi eğitim dönemi, bireyin tüm yaşamını etkileyecek derecede bir öneme sahiptir. Bu dönemde öğrenilen bilgi ve becerilerin, edinilen tutumların bireyin gelecek öğrenmelerini ve davranışlarını şekillendirdiği bilinmektedir. Bu nedenle, günümüz insanının sahip olması gereken bilimsel düşünme, yaratıcı düşünme, muhakeme etme, çok boyutlu düşünme becerilerinin geliştirilmesi için farklı eğitim yaklaşımları denenebilir. Ayrıca, Waldorf yaklaşımı doğaya dönük ve sanatsal aktiviteleri içeren bir yaklaşım olması yönüyle çocuğun gelişimine olumlu yönde katkı sağlamaktadır.

Araştırmadan elde edilen bulgulara dayanarak Türkiye açısından yeterince işlevsellik kazanmadığı düşünülen bu yaklaşıma ilişkin daha fazla bilgilendirme yapılabilir ve okul öncesi öğretmenlerinin lisans eğitiminde alternatif eğitim yaklaşımlarına ve bunların uygulamalı öğretimine daha fazla yer verilebilir. Ayrıca, Türk Eğitim Sistemi'ni şekillendiren Millî Eğitim Bakanlı̆̆ı tarafından Waldorf anaokulları açılabilir veya özel teşebbüs desteklenerek bu tarz alternatif okulların açılmasına öncülük edilebilir.

\section{Kaynakça}

Akdağ, B. (2006). Alternatif eğitim modelleri. Zil ve Teneffüs Dergisi, 6, 34-44.

Balay, R. (2004). Küreselleşme, bilgi toplumu ve eğitim. Ankara Üniversitesi Ĕ̆itim Bilimleri Fakültesi Dergisi, 37(2), 61-82. https://doi.org/10.1501/Egifak_0000000097

Balc1, A. (2013). Sosyal bilimlerde araştırma: yöntem, teknik ve ilkeler. Ankara: Pegem A Yayıncilik.

Bayhan, P. ve Bencik, S. (2008). Erken çocukluk dönemi programlarından Waldorf yaklaşımına genel bir bakış. Selçuk Üniversitesi Ahmet Keleşoğlu Eğitim Fakültesi Dergisi, 26, 15-25.

Çelik, M. (2013). Öğrenme çocuk ile büyür: Erken çocukluk eğitiminde Waldorf yaklaşımı. Erzincan Üniversitesi Eğitim Fakültesi Dergisi, 15(2), 39-51. ttps:/ / doi.org/10.1501/Ozlegt_0000000214

Edwards, C. P. (2002). Three approaches from Europe: Waldorf, Montessori, and Reggio Emilia. Early Childhood Research and Practice, 4(1), 2-14.

Glesne, C. (2012). Nitel araştırmaya giriş. (Çev. A. Ersoy ve P. Yalçınoglu). Ankara: Anı Yayincilik.

Gündüz, M. (2013). Modern eğitimin doğuşu ve alternatif eğitim paradigmaları. Bayburt Üniversitesi Ĕ̆itim Fakültesi Dergisi, 1(Özel Say1), 66-80. 
Kaya, D. ve Gündüz, M. (2015). Alternatif Eğitim ve Toplumsal Değişim Üzerindeki Etkisi: Waldorf Okulları Örneği. Milli Eğitim, 205, 5-25.

Kayg1sız, İ. (1997). Eğitim felsefesi ve Türk eğitim sisteminin felsefi temelleri. Ĕ̆gitim ve Yaşam, 8, 5-15.

Kılınç, F. E., Karayel, F. ve Koyuncu, M. (2018). Okul öncesi öğretmenlerinin farklı eğitim yaklaşımlarını bilme durumlarının incelenmesi. Erken Çocukluk Çalışmaları Dergisi, 2(2), 194-212. https:/ / doi.org/10.24130/ eccdjecs.196720182260

Koca, C. ve Ünal, F. (2018). Türkiye'deki bir Waldorf anaokulunun misyon, vizyon ve diğer anaokullarından farklı yönlerine ilişkin görüşlerin incelenmesi.

Eğitimde Nitel Araştırmalar Dergisi, 6(3), 185-206. https://doi.org/10.14689/issn.2148-2624.1.6c3s9m

Kotaman, H. (2009). Rudolf Steiner ve Waldorf Okulu. Yüzüncü Yıl Üniversitesi Eğitim Fakültesi Dergisi, 6(1), 174-194.

Memduhoğlu, H. B., Mazlum, M. M. ve Alav, Ö. (2015). Türkiye'de Alternatif Eğitim Uygulamalarına ilişkin Öğretmenlerin ve Öğretim Üyelerinin Görüşleri. Eğitim ve Bilim, 40(179), 69-87. https:/ / doi.org/10.15390/EB.2015.3913

Merkle- Yeşildağ, L. ve Yeşildağ, C. (2018). Yaşam için eğitim: Waldorf eğitimine giriş. Ankara: Vizetek Yayıncilik.

Miller, R. (2010). Eğitimde alternatifler niçin var?. Alternatif Eğitim e-Dergisi, 1, 24-26.

Patton, M. Q. (2014). Nitel araştırma ve değerlendirme yöntemleri. (Çev. M. Bütün ve S. B. Demir). Ankara: Pegem Akademi.

Paull, J. (2011). Rudolf Steiner and the Oxford conference: the birth of Waldorf Education in Britain. European Journal of Educational Studies, 3(1), 53-66.

Rawson, M. P. (2010). Sustainable teacher learning in Waldorf education: A sociocultural perspective. Research on Steiner Education, 1(2), 26-42

Steiner, R. (1996). Rudolf Steiner in the Waldorf School. Hudson: Anthroposophic Press.

Uhrmacher, P. B. (1995). Uncommon schooling: A historical look at Rudolf Steiner, anthroposophy, and Waldorf education. Curriculum Inquiry, 25(4), 381-406. https://doi.org/10.2307/1180016

Waldorf World List (2019). https://www.freundewaldorf.de/fileadmin/user_ upload/images / Waldorf_World_List/Waldorf_World_List.pdf adresinden 10/11/2019 tarihinde alınmıştır.

Yıldırım, A. ve Şimşek, H. (2013). Sosyal bilimlerde nitel araştırma yöntemleri. Ankara: Seçkin Yayıncılık.

\section{Summary}

\section{Introduction}

Alternative education in the most general sense; is an individual-oriented education approach that is part of the public system, which is outside the mainstream education and offers different learning experiences to the learner. (Kaya and Gündüz, 2015; Memduhoğlu, Mazlum and Alav, 2015). Although there are many different approaches to alternative education, especially in terms of pre-school education Montessori and Waldorf approaches are becoming more common in Turkey. These 
two approaches, which center the student, have their own philosophies, teaching methods and materials.

In Waldorf's approach, which ensures that every child can benefit from equal opportunities without discrimination, education should be harmonious and intertwined with nature and the student should be given the opportunity to progress at his own pace. The educational approach has brought a different dimension to the assessment in which students are not given a report card or grade in small classes. The aim of grades and report cards given since high school term is to make students aware of their own development and to increase their motivation (Kotaman, 2009). The Waldorf approach is child-centered and aims primarily to support the child's emotional and social development (Çelik, 2013). In addition, the child's multifaceted development should be ensured and in Waldorf approach these areas are expressed as mind, heart and ability (Akdağ, 2006; Edwards, 2002).

In the field review of the Waldorf approach, it was detected that studies conducted are usually of a compilation type and there are limited number of studies on this approach(Bayhan ve Bencik, 2008; Çelik, 2013; Kaya ve Gündüz, 2015; Kotaman, 2009). The aim of this study is to examine the views of pre-school teachers about Waldorf approach which is an alternative education model in preschool and its materials. Supporting different learning environments has become a necessity in terms of education systems and it is thought that examining the Waldorf approach, which has become widespread all over the world, will contribute to the description of the current situation and to bring similar studies to the literature.

\section{Method}

In this research, the phenomenological pattern of qualitative research methods was utilized. In order to determine the views of preschool teachers, an exhibition of various Waldorf materials was organized in the exhibition hall of Sivas Cumhuriyet University Faculty of Education. The materials presented in the exhibition were prepared by the researcher and posters were designed to introduce and inform about the Waldorf approach.

Participants of the research were identified using purposeful sampling technique, one of the improbable sampling methods, and the participants of the research were 8 preschool teachers who participated in the exhibition. During the data collection process, "teacher interview form" was used to get the opinions of the preschool teachers who are the participants of the research on Waldorf approach and materials. Descriptive analysis was performed by using MAXQDA 20 qualitative data analysis program.

\section{Discussion and Results}

According to the findings of the study, teachers find the Waldorf approach useful in preschool period. Participants stated that she would also recommend this approach to other colleagues. The positive aspects of the approach based on teacher views are identified as creative thinking, scientific thinking, self-expression, adapting to new situations, contributing to the individual progress of the child, considering individual differences, being in harmony with nature and hosting artistic activities. According to the results of Koca and Ünal's (2018) research, teachers express the mission of Waldorf kindergartens as providing education intertwined with nature and raising self- 
confident individuals. These characteristics, which are the basis of the Waldorf approach, are similar to the findings of this study.

The teachers stated that there may be some difficulties regarding the applicability of the approach as a negative situation in the Turkish education system. This may be due to the fact that alternative approaches in the Turkish education system have not achieved much. It is a known fact that the Waldorf approach has not yet been used effectively enough in Turkey and it is detected that there are only two Waldorf kindergartens in Turkey. Although it is not entirely designed based on Waldorf approach, it is known that there are some schools and classrooms in which the Waldorf approach is used. It is believed that this approach, which emerged in Germany, can be adapted to the Turkish education system by adhering to the basic features.

Teachers stated that Waldorf materials can be used in the areas of cognitive, language development, motor development and social emotional development, but most often they can benefit from this approach in teaching the gains in the field of cognitive development. Steiner (1996) states that the Waldorf approach can be used in many different development areas and that one of the main objectives of the approach is to contribute to the multifaceted development of the individual.

Based on the findings obtained from research, there is a need to inform more about this approach, which is thought as not gained enough functionalitiy for Turkey, and it can be given more weight to alternative education approaches in undergraduate education of preschool teachers and their practical teaching. In addition, Waldorf kindergartens may be opened by the Ministry of National Education, which shapes the Turkish education system, or private enterprises may be supported and the opening of such alternative schools may be pioneered.

\section{Araştırmanın Etik Taahhüt Metni}

Yapılan bu çalışmada bilimsel, etik ve alıntı kurallarına uyulduğu; toplanan veriler üzerinde herhangi bir tahrifatın yapılmadı̆̆ı, karşılaşılacak tüm etik ihlallerde "Cumhuriyet Uluslararası Eğitim Dergisi ve Editörünün" hiçbir sorumluluğunun olmadığı, tüm sorumluluğun Sorumlu Yazara ait olduğu ve bu çalışmanın herhangi başka bir akademik yayın ortamına değerlendirme için gönderilmemiş olduğu sorumlu yazar tarafından taahhüt edilmiştir.

\section{Authors' Biodata/ Yazar Bilgileri}

Didem KAYAHAN YÜKSEL Sivas Cumuriyet Üniversitesi Eğitim Fakültesi'nde Dr. Öğr. Üyesi olarak çalışmaktadır.

Didem Kayahan Yuksel works as Assist. Prof. Dr. in Faculty of Education at Sivas Cumhuriyet University.

Sebahattin KARTAL Sivas Cumuriyet Üniversitesi Sağlık Hizmetleri Meslek Yüksekokulu'nda Dr. Öğr. Üyesi olarak çalışmaktadır.

Sebahattin Kartal works as Assist. Prof. Dr. in Vocational School of Health Services at Sivas Cumhuriyet University. 